\title{
Drying of Limes in Oman Using Solar Tunnel Dryers
}

\author{
M. A. Basunia, H. H. Al-Handali, and M. I. Al-Balushi
}

\begin{abstract}
A solar tunnel dryer having 16 meter long and 2 meter width was designed and constructed to dry about $300 \mathrm{~kg}$ of freshly harvested limes per batch. The nearly one-third area of the tunnel base was used as the solar collector and the remaining two-third area as a dryer. The drying temperature could be easily raised by some $5-30^{\circ} \mathrm{C}$ above the ambient temperature inside the tunnel at an air velocity of approximately $0.15\left(\mathrm{~ms}^{-1}\right)$. The test was conducted with about $300 \mathrm{~kg}$ freshly harvested limes with initial moisture content of $86.0 \%$ (wet-basis) to analyze the performance of the dryer. The limes were dried to a final average moisture content of $10.0 \%$ (wet-basis) within 7 days ( 70 hours). The results indicated that the drying was faster in solar tunnel dryer ( 7 days) than the natural open air sun drying ( $>30$ days). The improvement in the quality of limes in terms of color, brightness and flavor was distinctly recognized.
\end{abstract}

Index Terms-Moisture content, tunnel dryers, limes.

\section{INTRODUCTION}

Limes are small citrus fruits. It is usually harvested when these become green or yellowish. They are used as a common food ingredient in many parts of Asia and as well as Central America. The dried lemons are called as black lemon - loomi or lumi in the Gulf countries. It is known as amani or omani in Iran, named after the main production country, Oman. Dried lemons are usually used to add a distinct citrus flavor and a sour tang to legumes and meat dishes. The dried lemons are crushed before usage, and then added to foods, examples are majboos, an aromatic rice dish prepared in the Gulf States. In Iran and Northern India, powdered loomi is also used to flavor rice.

There are various methods and techniques to dry limes. Each method has its own advantages and limitations. Dried products are becoming highly alternative to marketing than the freshly harvested products because of many advantages. Annual production of limes in Oman is estimated about 7000 metric tons [1]. The limes are still dried by traditional method of open air natural sun drying. This method of drying normally takes days, which are 25-35 days in Oman [2]. The traditional open air natural sun drying methods often yield poor quality. In most cases the drying yard is not properly fenced. So the product is not protected against dust, rain and wind, or even against insects, birds, rodents and domestic animals while drying. Soiling, contamination with microorganisms and infection with disease-causing germs

Manuscript received May 23, 2013; revised July 26, 2013. The financial support by the IG/AG/SWAE/10/04 for this study at the College of Agricultural and Marine Sciences, Sultan Qaboos University is greatly acknowledged.

The authors are with the Department of Soils, Water and Agricultural Engineering, Sultan Qaboos University, Oman (e-mail: basunia@squ.edu.om; hhandali@squ.edu.om; moha99@squ.edu.om ). are the result. The limes dried in this way have short shelf-life and may not be free from contamination. The solar drying facilities combine the advantages of traditional and industrial methods, namely low investment costs and high product quality.

The tunnel dryer is classified as a solar dryer that have been successfully tested under field conditions in about 30 countries under different climatic conditions in drying various agricultural products [3]-[9]. Unfortunately, solar tunnel dryer has not yet been tested here in Oman where solar energy is abundant and can be used for drying of limes and other agricultural products. The objectives of this study were to design and construction of a solar tunnel dryer, and to investigate its performance in drying lemons in Omani environment.

\section{MATERIAL AND METHOdS}

The prototype solar tunnel dryer consists of a flat plate air heating solar collector and drying tunnel, fabricated as a single unit (Fig. 1). The tunnel is $2.0 \mathrm{~m}$ wide, with a collector and dryer length of 6 and $10 \mathrm{~m}$, respectively.

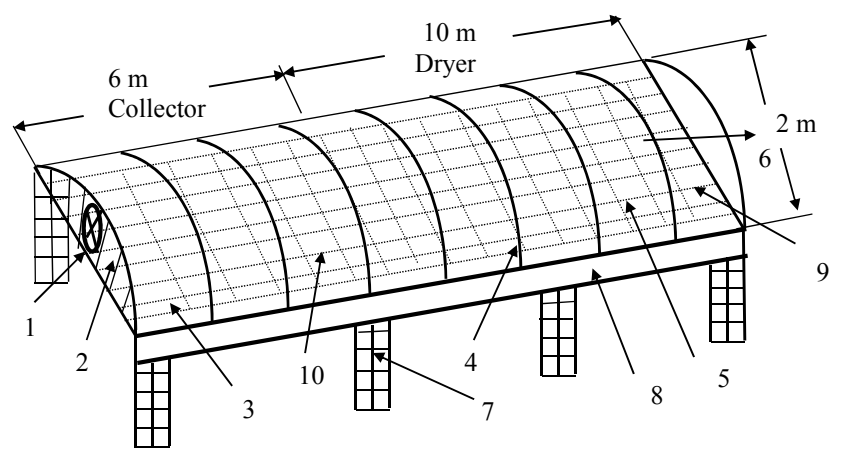

Fig. 1. A rough sketch diagram of a solar tunnel dryer used in this study (1-Air inlet to the collector, 2-AC fans, 3-Collector, 4-Light weight metallic fame, 5-Dryer, 6-Air outlet from the dryer,

7-Metalic frame, 8-Wooden frame to support bends; 9-Metalic wire mesh net, 10-Absorber plate(black plastic board)

The light-weight aluminum frames were used as the upper structure for the entire tunnel to support the transparent plastic cover. The tunnel was placed on concrete block substructures $500 \mathrm{~mm}$ above the ground surface. The ply wood planks $(0.9 \times 2.0 \mathrm{~m})$ of thickness $4 \mathrm{~mm}$ were used as the bed both for the dryer and collector parts of the tunnel to make the base of the tunnel almost air tight. Over the wooden base, black painted metallic sheets were used as the absorber plate in the collector section of the tunnel and light-weight steel wire mesh net was used over the wooden dryer base to dry the desired product. A $0.2 \mathrm{~mm}$ thick UV stabilized colorless polyethylene sheet was used as the transparent 
cover over the entire tunnel (collector and dryer area). The light-weight aluminum flat bars were bended as half-circles before fixing these with the wooden base of the tunnel.

A solar powered fan of 30 watt capacity was installed at the holes made on the wooden cover plat, $150 \mathrm{~mm}$ above the absorber metallic sheet at the air input side of the tunnel. Thus the drying air was forced from the collector region to the dryer region where the product is to be dried.

Twelve copper constantan thermocouples with an accuracy $\pm 0.5^{\circ} \mathrm{C}$ were connected within the tunnel, three at each of the mid-point of the collector and dryer as well as the junction point and exit of the dryer. The thermocouples were located at bottom ( $5 \mathrm{~cm}$ from base), middle $(50 \mathrm{~cm}$ from the base) and top (95 $\mathrm{cm}$ from the base) of the tunnel to measure the temperature profiles both in the vertical and horizontal directions of the entire tunnel. Two thermocouples were used to measure temperatures of the ambient air.

Also, a test with about one $\mathrm{kg}$ sample was conducted in open air (control) under natural convection with same thickness as in solar tunnel dryer to compare their drying rates.

\section{RESULTS AND DISCUSSIONS}

The no-load tests were conducted to know the temperature and air flow characteristics at different weather conditions and also, the temperature gradient both in the collector and dryer regions of the tunnel. Fig. 2 shows the variations of ambient, collector and dryer temperatures with time of the day. The drying air temperature could be easily raised by some $5-30^{\circ} \mathrm{C}$ above the ambient temperature at an air flow rate of $0.1-0.3 \mathrm{~ms}^{-1}$.

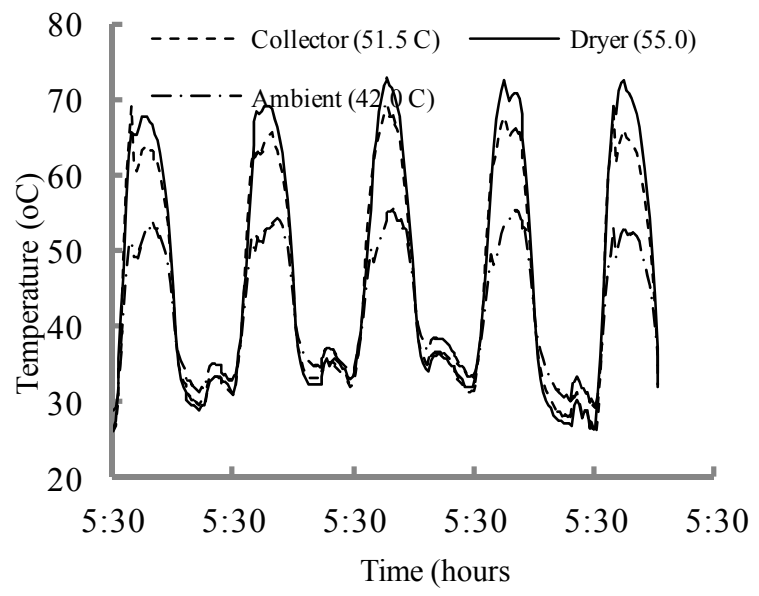

Fig. 2. Variations of collector, dryer and ambient temperatures with time (5:30 AM - 5:00 PM) under no-load.

The difference between the drying air temperature and ambient temperature gradually increased from morning till mid-day then gradually fall in the afternoon (Fig. 2). The highest temperature $74^{\circ} \mathrm{C}$ was observed at around 12:30 PM. This indicated that solar tunnel dryer can be easily used to dry limes. In no load tests the maximum difference between the average temperatures of the dryer and collector parts was about $5^{0} \mathrm{C}$. This indicated the uniformity of temperatures inside the entire tunnel. There was almost no temperature gradient in the vertical direction of the whole tunnel, both in the dryer (Fig. 3) and the collector (Fig. 4) parts of the tunnel. Fig. 5 show the temperature profiles in the horizontal direction through the bottom along the breadth wise center of the tunnel.

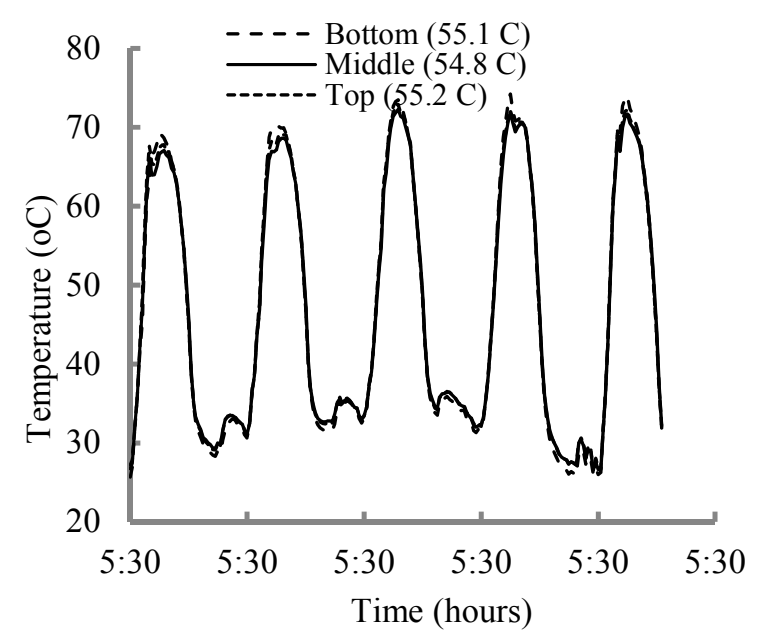

Fig. 3. Temperature profile in the vertical direction of the dryer with time (5:30 AM - 5:00 PM) under no-load.

There was almost no considerable amount of temperature gradient observed in the horizontal direction both in the dryer and collector parts of the tunnel due to proper mixing of the drying air by the fan (Fig. 5). Similar trends of temperature profile were also observed through the middle and top of the tunnel.

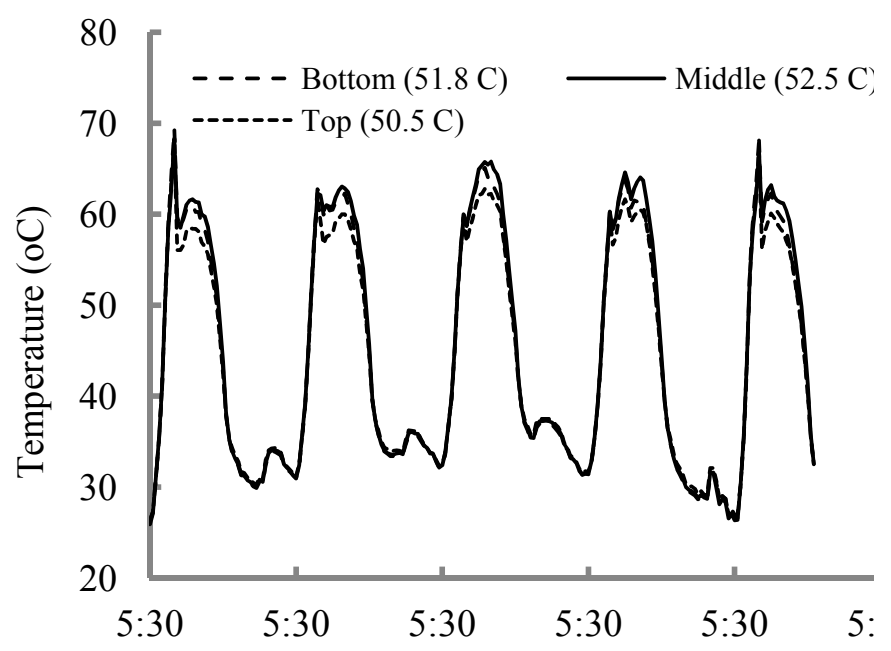

Fig. 4. Temperature profile in the vertical direction of the dryer with time (5:30 AM - 5:00 PM) under no-load.

A full load test with around $300.0 \mathrm{~kg}$ freshly harvested limes was conducted to study the dryer performance on May 23-29, 2012. The average initial moisture content of the freshly harvested limes collected from the local market was $86.0 \%$ (wet-basis). The limes were spread on a wire mesh net in a single layer thickness placed over the plywood bottom of the drying section of the tunnel. After termination of first day drying, the product was kept undisturbed in the dryer closing both sides of the tunnel by polyethylene sheet so that air could not passed through the tunnel. Samples were collected for moisture content determination at the end of drying and it was found around $10.0 \%$ (wet-basis). 


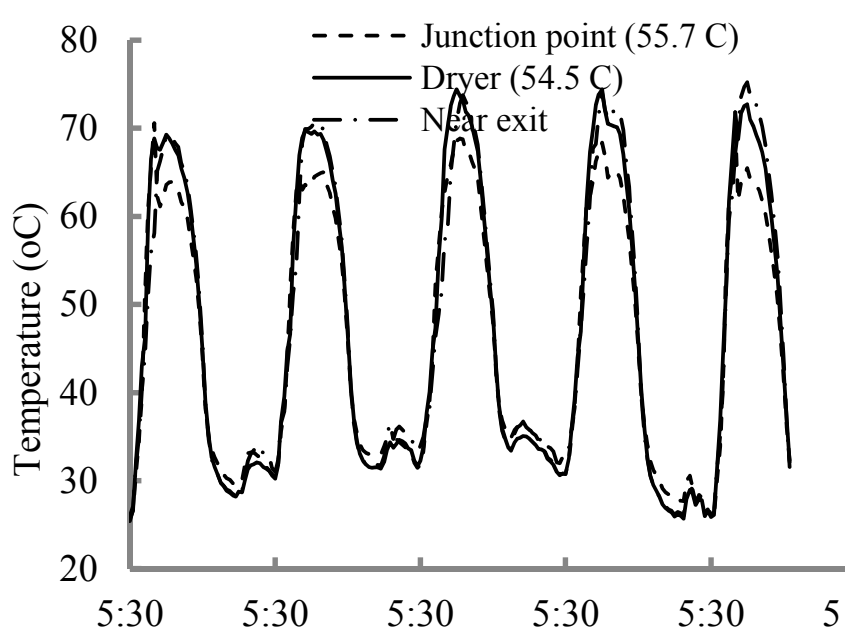

Fig. 5. Temperature profile through the bottom of the whole tunnel dryer with time (5:30 AM - 5:00 PM) under no-load.

The variations of the dryer and collector air and the ambient air temperatures with drying time (5:30-17:00 hr/day) in seven days have shown in Fig. 6. Fig. 7 shows the variation solar irradiance with time of the day, recorded for the first five days of drying. It is clearly indicated that an average $1000\left(\mathrm{Wm}^{-2}\right)$ solar energy was incident on the horizontal surface which was used in drying limes. The average day time drying air and ambient temperatures were $53.0^{\circ} \mathrm{C}$ and $42.0^{\circ} \mathrm{C}$, respectively, for the seven days of drying. The average temperature in the collector part was lower than the average temperature in the dryer part because of the presence fan at the air entrance side of the collector. It seemed that more limes could be dried in same time by increasing the thickness of the limes in the dryer section of the tunnel as the potentially of the drying air was partially used.

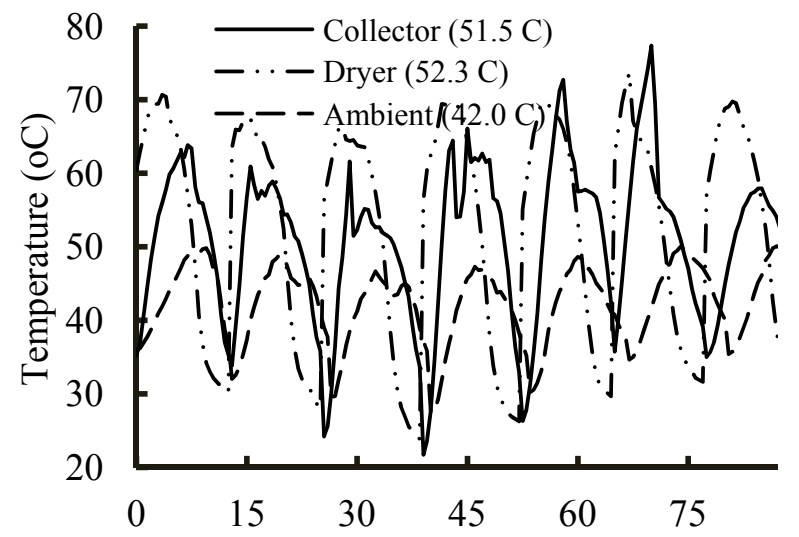

Fig. 6. Variations of collector, dryer and ambient temperatures with drying time (5:30 AM-5:00 PM each day)

\section{CONCLUSIONS}

This paper describes the design, construction and experimental investigation of a solar tunnel dryer. The no-load tests clearly indicated that the drying temperature can be easily raised to $5-30^{\circ} \mathrm{C}$ above the ambient temperature while the average air flow velocity inside the tunnel was $0.1-0.3 \mathrm{~m} / \mathrm{s}$. The average drying air temperature could be easily attained $50-55^{\circ} \mathrm{C}$.

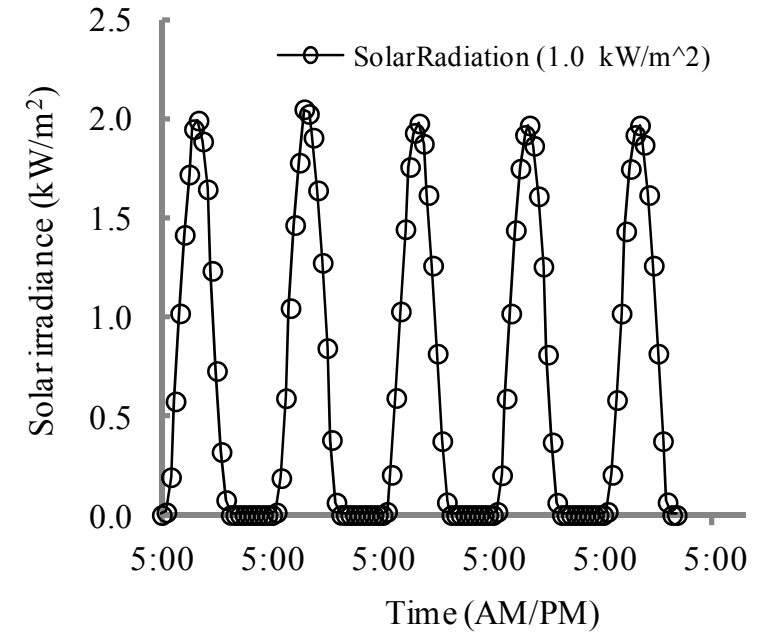

Fig. 7. Variations of total (beam and diffuse) solar radiation on horizontal surface with drying time (5:30 AM-5:00 PM each day).

The experiments were carried out with $300.0 \mathrm{~kg}$ freshly harvested limes and the performance of the dryer was compared to open air natural sun drying. A considerable reduction in drying time (30-7 days) in comparison with natural open air sun drying was obtained. These investigations show that solar tunnel dryer can be used for low temperature drying of limes and other agricultural products in the rural areas of Oman where electricity is not available.

\section{REFERENCES}

[1] MAF. "Ministry of Agriculture and Fisheries Directorate," Annual statics report, Oman, 2009.

[2] M. A. Basunia, H. H. Al-Handali, M. I. Al-Balushi, and M. S. Rahman, "Annual research progress report on performance evaluation of a solar tunnel dryer for drying lemons in Oman," CAMS, Sultan Qaboos University, 2012.

[3] P. Schirmer, S. Janjai, A. Esper, R. Samitabhindu, and W. Muhlbauer, "Experimental investigation of the performance of the solar tunnel dryer for drying bananas," Renewable Energy, vol.7, no. 2, pp. 119-129, 1996.

[4] G. A. Mastekbayeva, M. A. Leon, and S. Kumar, "Performance evaluation of a solar tunnel dryer for chili drying," presented at the ASEAN seminar \& Workshop on drying technology, Phitsanulok, June 3-5, 1998.

[5] B.K. Bala and M. R. A. Mondal, "Experimental investigation of solar tunnel dryer," Drying Technology, vol. 19, no 2, pp. 1-10, 2001.

[6] M. A. Basunia and T. Abe, "Thin-layer solar drying characteristics of rough rice under natural convection," Journal of Food Engineering, vol. 47, pp. 295-301, 2001a.

[7] M. A. Basunia and T. Abe, "Design and construction of simple three-shelf solar rough rice dryer," Agricultural Mechanization in Asia, Africa and Latin America, vol. 32, no 3, pp. 54-59, 66, 2001b.

[8] A. A. EI-Sebaii, S. Aboul-Enein, M. R. I. Ramadan, and H. G. El-Gohary, "Empirical correlations for drying kinetics of some fruits and vegetables," Energy, vol. 27, pp. 845-859, 2002.

[9] B. K. Bala, M. R. A. Mondal, B. K. Biswas, B. L. Das Choudhury, and S. Janjai, "Solar drying of pineapple using solar tunnel dryer," Renewable Energy, vol. 28, pp.183-190, 2003.

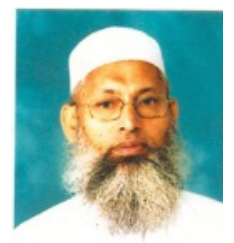

M. A. Basunia is currently an assistant professor, Department of Soils, Water and Agricultural Engineering, Sultan Qaboos University, Oman. His key responsibility is to teach at undergraduate and graduate levels students and supervising their research works. Dr Basunia is an agricultural engineer, specialized in Farm Machinery, Agricultural Process Engineering, Post-harvest Technology and use of Renewable Energy in Agriculture. He is author of more 
35 research papers published in reputed journals in his field. He also pursued JSPS postdoctoral research work at the Ehime University, Japan, during 1998-2000. He was also a professor and former Head, Department of Farm Power and Machinery at Bangladesh Agricultural University (BAU), Mymensingh, Bangladesh.

H. H. Al-Handali obtained secondary school in Oman and then studied Technician Diploma in Agriculture at Sunderland Polytechnic, UK, during 1985 to 1987 . He also did B.Sc. course in Computer Aided Design at the University of Central of England, Birmingham, UK in 2006. He has been servicing as a Technician to the Department of Soils, Water \& Agricultural Engineering, Sultan Qaboos University,
Oman, since 1987. His responsibilities include undertaking work at the workshop and supervising Power and Machinery laboratories.

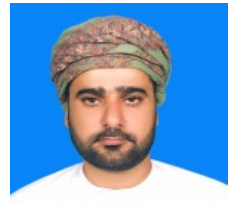

M. I. Al-Balushi obtained B.Sc. in Agricultural Mechanization and M.Sc. in Bioresource and Agricultural Engineering from Sultan Qaboos University, Oman, in 1996 and 2003, respectively. He had been working as a Technician with the department of Soils, Water and Agricultural Engineering since 1996-2011 and then promoted to the rank of Superintendent to the department from 2012. He has a good number of publications as co-other in different journals of Agricultural Engineering. His main responsibility is to provide technical support to the department. 